\title{
Building Bridges: On Effective Weather Communication to, and with, Vulnerable Populations
}

\author{
Matthew J. Bolton, ${ }^{1}$ H. Michael Mogil, ${ }^{2}$ and Stacie H. Hanes ${ }^{3}$ \\ ${ }^{1}$ College of Arts and Sciences, Saint Leo University, Saint Leo, FL \\ ${ }^{2}$ How the Weatherworks, Naples, Florida \\ ${ }^{3}$ U.S. National Weather Service, Blacksburg, VA
}

Correspondence regarding this paper should be addressed to Matthew Bolton, College of Arts and Sciences, Saint Leo University, Saint Leo, FL 33574. Email:

Matthew.Bolton@email.saintleo.edu

Preprinted 2021. 


\begin{abstract}
Weather renders all people vulnerable, but due to various factors some are more naturally vulnerable than others. What of those vulnerable populations and individuals who cannot take, or are limited in taking, protective actions? This paper contributes to the mission of the WeatherReady Nation initiative (WRN), established by the U.S. National Weather Service, by shining light on weather communication considerations for those on the autism spectrum and those with color vision differences. It also discusses ongoing efforts centered around the Deaf and hard-ofhearing and those who are blind or who have limited vision, and discusses problems existing in weather communication for vulnerable populations at-large. The first section defines vulnerability and clarifies associated concepts while the second section, on ways to improve weather communication practices for autistic people and those who are blind, vision-limited, Deaf, hard-of-hearing, and those with color vision-processing differences, focuses on the importance of recognizing lived, vulnerable population experience in weather messaging efforts and the use of language in communicating with the aforementioned populations.
\end{abstract}




\section{Building Bridges: On Effective Weather Communication to, and with, Vulnerable Populations}

Weather renders all people vulnerable. All of us are threatened by the myriad meteorological hazards existing in nature; it is just that some (perhaps most) of us have taken, and are more easily able to take, action to mitigate these threats. What of those vulnerable populations and individuals who cannot take, or are limited in taking, protective actions? This paper contributes to the mission of the Weather-Ready Nation initiative (WRN; see https://www.weather.gov/wrn/), established by the U.S. National Weather Service (NWS), by shining light on weather communication considerations for those on the autism spectrum and those with color vision differences. It also discusses ongoing efforts centered around the Deaf and hard-of-hearing and those who are blind or who have limited vision, and discusses problems existing in weather communication for vulnerable populations at-large.

The first section defines vulnerability and clarifies associated concepts while the second section, on ways to improve weather communication practices for autistic people and those who are blind, vision-limited, Deaf, and hard-of-hearing, and who have color vision-processing differences, focuses on the importance of recognizing lived, vulnerable population experience in weather messaging efforts and the use of language in communicating with different populations.

\section{Defining Vulnerability}

When we refer to the concept of a vulnerable population, we mean people who are unable, based on innate individual differences or external societal factors, to anticipate, cope with, resist, and/or recover from, the impacts of disasters (Blaikie et al., 2004; Hufschmidt, 2011; Patterson et al., 2010; Wisner, 2016). A list of such individuals includes those who, for example, 
are physically disabled, Deaf or hard-of-hearing and/or visually-limited ${ }^{1}{ }^{1}$ those who have cognitive processing differences or disabilities; single, working parents; pregnant women; children; the elderly; people of lower educational and/or socioeconomic standing; people without vehicles or who cannot drive for some other reason; people who speak non-native languages (this could be English or another language, depending on the country); people living in a floodvulnerable area; people who may have had their homes damaged by a fire (who could be at-risk from subsequent mudslides), tornado, or other severe weather element; and the homeless, although any one of these individuals could have a psychological or other, possibly medical, condition as well.

Even those who are economically well-off but living in a home not built to recent safety standards could be considered vulnerable beyond the risks of daily life. So, too, in a medical sense, could we consider people with particular conditions (who may need to be concerned with the upkeep of medication or other supplies), food allergies, or other dietary needs. A widelyadopted public health perspective also includes people in hazardous working conditions (on oil rigs; in the police, military, or emergency response) and prisoners.

The definition of "vulnerability" above clearly and effectively considers psychological, sociological, and public health perspectives with respect to an associated element: Access and/or functional need(s) (AFN), that naturally renders some degree of vulnerability. Access needs generally refer to societal resources a person needs in the course of daily life (United States [U.S.] Department of Health and Human Services [DHHS], 2021). These include but are not limited to social services; disability, medical, and other accommodations; necessary information

\footnotetext{
${ }^{1}$ When talking about vision-impaired people, we mean those who are blind or who have low vision above and beyond the ability of corrective lenses or surgeries to fix.
} 
(flow of which could be impeded if, for example, a person speaks another language);

transportation; and medications. For example, elderly people in assisted living facilities are subject to institutional resources and crisis plans, and many factors can converge with respect to these, complicating evacuation or shelter-in-place orders.

Functional needs have been defined as "restrictions or limitations an individual may have that requires assistance before, during, and/or after a disaster or public health emergency" (U.S. DHHS, 2021). We see these as directly related to the individual characteristics of persons with various conditions which predispose to risk. $^{2}$ Sensory sensitivities in autism, for example, may compel the individual to wear certain kinds of clothing and these may have been lost after a devastating tornado (the risk in this case being a lack of safety and comfort). A person with major depression may not have access to psychotherapy services and/or a support animal after a hurricane (a time when he or she may especially need them).

Put another way, AFNs involve societally-derived factors and individual, psychobiological characteristics that enable vulnerability. Breaking it down this way, we can understand how various sociological and psychobiological components might overlap: A visionlimited or blind person is highly dependent on others for transportation; someone with epilepsy may be unable to obtain necessary medications while snowed-in after a blizzard. Schizophrenia, dementia, and Alzheimer's, for further demonstration, are three mental disorders that could fit within both categories by virtue of the individual's psychological disposition necessitating assisted care and living arrangements. The individual would then be subject not only to the

\footnotetext{
${ }^{2}$ We do not like to think in the terms of abnormality that the DHHS' definition implies, believing rather in the individual's innate humanity.
} 
predilections of their disordered state but also to access vulnerabilities associated with the needs and limitations of the care facility.

Although it is unrealistic to expect that the needs of all populations will, or even can, be met, weather messengers should be aware of and focus on needs in each of several broader categories of individual psychobiological difference (the physical, auditory, visual, and cognitive domains), as appropriate for day-to-day and particular severe weather situations. Our work, together and with other colleagues, dating to 2015 , has focused on matters related to autism spectrum conditions (Bolton, 2018a, 2018b, 2018c; Bolton et al., 2020; Bolton et al., 2017; Bolton \& Blumberg, 2015; Bolton \& Hanes, 2020; Hanes \& Bolton, 2020) and color vision (Bolton \& Blumberg, 2015; Bolton \& Mogil, 2018a, 2018b; Bolton et al., 2016; Bolton et al., 2019).

\section{Improving Vulnerable Populations Communication}

This brings us to a focus on some of the challenges faced by autistic, Deaf and hard-ofhearing, and blind and vision-limited individuals, continuing our focus on primary domains of psychobiological difference. Before discussing concerns for the Deaf and hard-of-hearing, autistic people, and blind and vision-limited, we want to share some more general research findings.

First, beyond the control of even the most well-meaning meteorologist, socioeconomically-disadvantaged people are more physically at risk to natural disasters and dangerous weather because they very often can't afford to engage in recommended preparedness and protective action activities and may not receive early hazard messaging, if they receive these messages at all (Wisner et al., 2004). They also are typically live in lower-quality housing 
located in more damage-prone areas, and some may be homeless (Fothergill \& Peek, 2004; Wisner et al., 2004).

Second, disability is associated with an inability to evacuate when faced with approaching tropical cyclones. In 2002, van Willigen, Edwards, Edwards, and Hessee compared the hurricane evacuation experiences of North Carolina residents who had a disabled family member living with them to residents who did not, during Hurricanes Bonnie, Dennis, and Floyd. Reported evacuation rates ranged from 9-25\% lower for households with a disabled family member. Contributing factors, themselves associated with a lack of evacuation planning among disabled individuals (Fox et al., 2007; Spence et al., 2007), in the non-evacuation decisions included transportation issues and a dearth of accessible shelters. Altogether, these findings have significant implications for disabled individuals in need of evacuation or shelter services; they allude to wider problems relating to social support for, and/or the design of educational and outreach materials on, evacuation procedures that do not consider these populations (Phillips \& Morrow, 2007; Rowland et al., 2007; White, 2006).

Researchers have also found that children, especially those with disabilities or functioning differences, are particularly vulnerable in times of dangerous weather. This could relate to the fact that, by their very nature, all children are dependent on parents or other guardians. Yet, it also appears that little formal planning (within evacuation shelters and by emergency officials for medical and other necessary support in the event critical infrastructure is lost) addresses their needs (see e.g., Mitchell et al., 2008; Osofsky et al., 2007; Peek \& Stough, 2010; Phillips \& Morrow, 2007). Care for children (including their access needs), rather, tends to fall on parents, guardians, or other caretakers whom it is presumed in most, if not all, cases, will inform, warn, and adequately protect them. Reasons given by emergency management officials 
for this lack of attention include such factors as inadequate personnel/staffing, or the officials' own limited knowledge of disabilities and/or vulnerable populations.

Researchers (e.g., Casserly, 2006; Rooney \& White, 2007) emphatically draw attention to the finding that emergency planners and responders are often ill-equipped to handle various AFNs. To understand the drastic societal impact associated with this outcome, consider the roughly 100,000 children who were evacuated and geographically displaced from New Orleans due to Hurricane Katrina (Abramson \& Garfield, 2006; Hemingway \& Priestly, 2006; Redlener et al., 2007). Roughly 33,000 of these children had at least one chronic medical condition, and many found their access to health insurance, prescription medication, and specialized medical equipment and services severely compromised in the hurricane's aftermath (Abramson \& Garfield, 2006; Osofsky et al., 2007; Redlener et al., 2007).

\section{Concerns for the Deaf and Hard-of-hearing}

Two of the most common problems faced by the Deaf and hard-of-hearing in receiving weather messages are brought about by AFNs. Technological and broadcast practices, including poor adherence to regulations and protocols for the provision of closed captioning services on one hand and the physical mannerisms and broadcast presentation techniques and styles of on-air meteorologists on the other, may inhibit timely receipt of critical warning information. In a 2003 Alabama tornado event, some local-market television stations failed to provide closed captioning services (Phillips \& Morrow, 2007). As a result, Deaf and hard-of-hearing university students in the warned area, unsure of the developing situation and lacking additional means to receive the information, left their dormitories while the event was still underway to go to the school's disability support offices to learn about possible dangers. Further, Deaf and hard-of-hearing individuals who rely on lip reading to properly interpret others' speech report being negatively 
impacted when broadcast meteorologists turn their backs or sides to the camera and do not properly spot-track their heads to the viewer-facing camera (Phillips \& Morrow, 2007).

The Deaf and hard-of-hearing also typically face some of the worst hardships and difficulties during and after natural disasters, in terms of being able to meet their everyday needs, because they are dependent on others and/or technologies that are unavailable in the disaster's wake (White, 2006). While this problem is more for emergency responders to address by ensuring the availability of an adequate numbers of sign language interpreters and, where possible, speech-to-text technologies on-site, sign language-trained meteorologists working within a Community Emergency Response Team (CERT) capacity, or perhaps as part of the onsite emergency management team, can also provide such support. The Deaf and hard-of-hearing, finally, also face significant issues of accessibility when it comes to acquiring needed communication-supporting technology aids. Weather radios are for hearing people a roughly $\$ 30$ purchase, but add-on the strobe light and pillow-shaking attachments created to make them usable by those with limited to no hearing capacity and this easily becomes an expenditure upwards of $\$ 100$ (see https://www.weather.gov/nwr/special_needs for more information). Some of the responses meteorologists have made to better communicate to and with the Deaf and hardof-hearing include:

(1) Alabama NWS offices have partnered with the Alabama Department of Rehabilitation Services, which serves the state's Deaf population. This has enabled statewide, hearing-loss-accessible SKYWARN® spotter training as well as the provision of NOAA Weather Radios with strobe light attachments to alert Deaf individuals of weather threats. 
(2) NWS offices in Texas have partnered with, and recognized as a Weather-Ready Nation Ambassador, the Texas School for the Deaf, a residential school for the Deaf.

(3) The Nashville NWS office has engaged in Deaf weather communication efforts across Tennessee.

(4) The NWS introduced a nationwide lightning safety awareness campaign and slogan for the Deaf and hard-of-hearing in recent years ("See a Flash, Dash Inside;" for more information, see https://www.noaa.gov/stories/see-flash-dash-inside-new-lightningsafety-slogan-rolls-out and https://www.weather.gov/safety/lightning).

\section{Concerns for People on the Autism Spectrum}

It is often difficult to tell if a person has a particular condition when its characteristics are subtle. Autistic people, for example, can often ably mask, or camouflage, their weaknesses in social situations (Lai et al., 2017; Hull et al., 2017). This is especially true if the individual has learned to manage, or is not functionally-affected by, autism's more stereotypical characteristics.

Still, autism's presentation varies, and many on the spectrum face significant life challenges. The condition is characterized by difficulties in social communication, unusually narrow interests and repetitive behaviors, and sensory processing differences (American Psychiatric Association, 2013). Recent data suggests its occurrence in roughly 3.5 million people in the United States (Baxter et al., 2014) and some 52 million people worldwide (Baio et al., 2018), with a U.S. prevalence rate of 1-in-54 (U.S. Centers for Disease Control, 2020) and global prevalence of 1-in-132 individuals (Baio et al., 2018). ${ }^{3}$

\footnotetext{
${ }^{3}$ Note, prevalence increases over the last several years are generally understood as being linked to changing and improved diagnostic practices rather than an actual increase in occurrence.
} 
For nearly all but those most severely limited in day-to-day functioning, who are dependent on others, most autistic people are likely uninhibited in actually receiving weather information. In fact, some of our research (Bolton et al., 2020) suggests they manifest high degrees of weather salience-psychological attention to weather. Concerns about storm phobia for autistic people notwithstanding based on what is known about intolerance of uncertainty and anxiety in autism, ${ }^{4}$ the greatest challenges for autistic people in weather communication are likely related to social perceptions and weather safety and preparedness knowledge.

The prejudice and stigma faced by people on the spectrum are no secret (see, e.g., Bolton \& Ault, 2018; Bolton, Ault, \& Meigs, 2020; Brosnan \& Mills, 2016; Morrison et al., 2019; Sasson et al., 2017; Sasson \& Morrison, 2019 for empirical evidence, and Silberman, 2015, for a historical-journalistic review). Bolton \& Hanes (2020) specifically express concerns about treatment of autistic people in the weather enterprise and discuss the amelioration of bias among meteorological professionals. Meteorologists are most likely to interact with autistic people in the course of participation in school talks, station facility tours, and various public weather and disaster-related outreach events. It is important they act, whether they know or suspect an individual is on the spectrum, from a place of empathy. Their kind, thoughtful, and supportive interacting could be of great personal significance to the autistic individual who holds meteorological interest.

To combat weather safety knowledge shortfalls among autistic people in the U.S., Hanes and Bolton (2020) created an autism-accessible SKYWARN® storm spotter and weather safety program. Briefly, the protocol involves recognizing and understanding that those attending may

\footnotetext{
${ }^{4}$ See Liss et al. (2008), Neil et al. (2016), and South and Rodgers (2017); and see Bolton et al. (2020) for discussion on autism and perceptions of weather randomness.
} 
interpret and understand hazardous weather conditions differently than a typical SKYWARN® audience, and adjusting accordingly. Considerations include: Adapting content to include more visuals and less technical jargon; sticking to concrete action statements; exercising noise control and minimizing videos and other content that may be disruptive; and keeping classes small to minimize distractions. The instructor(s) must understand that each attendee will process the information presented differently, and that behaviors exhibited may not be what they seem (for example, apparent disinterest may be rapt attention; frequent fidgeting may be a sign of intense concentration).

Hanes and Bolton's efforts with respect to autism, and the aforementioned NWS outreach to the Deaf and hard-of-hearing, underscore the value of localized endeavors by individual meteorologists to support vulnerable populations. In contrast, the WRN program has tried a onesize-fits-all, outsourced approach to intellectual disability accommodation that has been neither widely adopted nor advertised like other WRN efforts (see https://www.weather.gov/wrn/intellectualdisabilities).

\section{Concerns for the Blind and Those with Low Vision}

Work to account for blind and vision-limited people in weather messaging is in its infancy, but researchers are fast uncovering the weather communication needs of these individuals. For example, recent work (Sherman-Morris et al., 2020) has revealed access issues in that a lack of audio for TV warning crawls and the descriptiveness with which broadcasters communicate the threat and warning message are two major barriers to the receipt of information. Study participants mentioned wanting to hear their specific location; sometimes being confused about the location of hazards; and experiencing difficulty imagining and judging distances and spatial information regarding locations relative to their own. 
These individuals may have a reduced capacity to confirm, and then act on, weather information through additional and alternative sources, and in turn rely more heavily on broadcast meteorologists (who should remain wary of over-hyping events). While we recognize the difficulties inherent to any broadcast severe weather situation, and that these often require split-second decision-making, this issue of descriptiveness is a matter for which meteorologists at least need heightened awareness (Hobson \& Cote, 2019).

\section{The Need for Lived Experience}

One crucial concept in this discussion is the notion of communicating not just to, but also with, vulnerable populations. Although all behavior, even that which is not reciprocated, is a form of communication, information flow is translational, occurring between people. It requires reciprocation and has to occur between people-without a mutually-facilitated, two-way flow of information, what goes on is simply one person transmitting at another, with no real learning or meaningful exchange taking place.

Weather communication that aspires to work across communities and populations must work in the same manner. Meteorologists do not need actual feedback, in the moment, about the receipt of a hazard message. People do not need to call-in to their local TV station to confirm with the on-air meteorologist that they took shelter during a tornado (although sometimes people do this). Still, weather communication is a collaborative, ongoing process between meteorologists and the public; messages are refined and subsequently modified when the meteorologist learns the ways in which the information-consuming public receives and then responds to past messaging. Meteorologists are constantly refining their messaging repertoire based on the way people respond or report about their response. 
To reach vulnerable populations, however, weather messengers must go further. Effective communication to these individuals begins by wiping clean one's assumptions about what it means to craft an effective message and approaching the messaging from a participatory perspective (see Fletcher-Watson et al., 2018, for examples of how this has worked between autism researchers and autistic people to conduct more inclusive, fair, and effective autism science). Meteorologists cannot presume to know the needs of vulnerable populations a priori, as each differs in their specific weather safety and preparedness needs. It is imperative that meteorologists take care to consider each group's unique sociocultural and psychological contexts and aim to include in the weather messaging development process individuals who actually live with AFNs. This partnership transforms the mere one-way information transmission of traditional forecasting into a mutual exchange benefiting both the vulnerable population and the working meteorologist (the former receives better information; the latter becomes more effective in protecting life and property).

Interfacing with different communities in such a collaborative and dialogic manner includes the recognition that lived experience is just as important in and valuable to the weather messaging process as formal learning credentials, and ensures that real needs are more adequately met than by learning alone. Supports and interventions based on learning alone, however well-meaning, are rooted in assumptions for needs that may or may not exist. Information learned in the course of, or after, obtaining a $\mathrm{PhD}$ or other degree or certification can tell us what is "known" about a condition or a group. It cannot, however, let us step into that condition and feel exactly how it is to be blind or deaf or to experience the world as a place where seemingly-ordinary, everyday sensory experiences (such as going to the store for groceries and being surrounded by all manner of lights, sounds, smells, and people) are entirely 
overwhelming. A both-and approach incorporating the lived experiences and perspectives of vulnerable populations, with individuals from the populations included alongside learned professionals, as equal partners in the development of said messaging, is the only one that will foster truly inclusive and effective messaging.

Any well-informed overhaul of weather-messaging principles and practices necessitates understanding the overlap of sociocultural context and lived experience, but how does one go about doing this? One way forward includes the fostering of cultural relativism: Seeking to understand another person's beliefs and behaviors from the perspective of their culture, rather than one's own. In other words, within this context the meteorologist holds in mind the target population's frame-of-reference-incorporating the unique perspective of the population-when designing weather messages, rather than designing the message based off of the meteorologist's implicit knowledge and experiences. This involves becoming familiar with the targeted community's norms and contexts through cultural immersion and observation.

\section{Reference Language and Respect for Communities}

Lexical familiarity-in this case, a familiarity based on the shared language of the groupis one cultural element the NWS already embraces in some of its WRN messaging (for the Deaf and hard-of-hearing; see https://www.weather.gov/wrn/dhh-safety). Have you noticed our capitalization of “deaf” throughout this paper? There's a very specific reason for this: Capital "D" Deaf represents a self-identification and acknowledgement by deaf people that those with hearing-loss have their own culture (shared beliefs, attitudes, values, and norms), persecutions, and needs. The capital " $\mathrm{D}$ " is used in reference to a specific person, or persons, with the physical condition of deafness, who embrace(s) the condition's cultural aspects. It is also used when talking about events or cultural issues among the Deaf. Lowercase " $d$ " deaf is viewed as a verb 
acceptable to Deaf people only in directly describing deafness as a condition. For example, "This person became deaf at age 3 , but later joined the Deaf community." Deaf culture ascribes a high degree of meaning to reference language, which tends to be viewed not just pragmatically but through a very personal lens as well.

Using sign language to communicate holds a certain sanctity for the Deaf community (Padden \& Humphries, 1990, 2005). Deaf individuals have historically been made to adapt; living and attempting to communicate from an oralist tradition, more like those with hearing, rather than being allowed to pursue the methods which work best for them. They have, for example, been forced into speech classes by hearing people seeking their "normalization," and discouraged or even punished for using sign language. Like certain sections of the autistic community, who on the whole have historically faced atrocious societal treatment, ${ }^{5}$ Deaf people have fought-and fight-to freely pursue their own language that works best for them, and culturally they distinguish themselves from people who lose their hearing to illness, trauma, injury, or age. The NWS has integrated these various understandings into its hearing-related messaging, but meteorologists must recognize the importance of becoming familiar with the language and vernacular of every group that is targeted for enhanced messaging.

Vision-limited and blind individuals do not seem to share the consensus views of Deaf people, that they share group norms (Hopfe, 1999; Pierce, 2008), while many on the autism spectrum do believe in a shared culture. Autistic people, further, prefer a variety of terms in reference to themselves and autism itself (Bolton, 2018c; Kapp et al., 2013; Kenny et al., 2016). Those who feel autism is a non-disabling difference and intrinsic part of who they are prefer

\footnotetext{
${ }^{5}$ Extreme social distancing and ostracism, institutionalization, forced sterilization, and even mass euthanasia efforts, for example. Steve Silberman's Neurotribes provides an excellent look at the way people on the spectrum have historically been treated, while also tracing the condition's roots.
} 
"identity-first" language (that is, "autistic person"). Others-including most professionals-wish to separate the individual from the perceived disabling nature of the condition with "person-first" language (for example, "person with autism"). Note that here, however, a capital "A" is not used; nor is capital "B" typically used among the blind.

To reference autism itself, some (present authors included) have adopted "autism spectrum condition" over the more well-known autism spectrum disorder terminology. This is because "condition" may serve as a less-stigmatizing medical/diagnostic term that can allow support to be rendered to those in need (Baron-Cohen, 2017). A more neutral term with which both sides seem to agree-there is a debate around the use of identity- vs. person-first terms-is "person on the autism spectrum." Something we want to emphasize is the flexibility of condition-based language. It may sometimes be stated that a person has an autism spectrum condition. This, although it uses person-first language, actually refers to the condition, or specific state of being, the person is in (here, an autistic state of being), just as, for example, one would state a person in a medical emergency is in critical condition or has a medical condition. "Condition" can thus be multifaceted and used across situations based on context.

It is worth noting that whereas the Deaf community will accept hearing and non-hearing alike within their cultural traditions (although sign language fluency is typically expected), the autistic community is generally highly resistant to non-autistic people (whom they have coined "neurotypicals" to reference the majority typical, non-autistic brain) taking part. These are highly complex but important matters with which to be familiar; they could mean the difference between successful and unsuccessful community engagement. Hence, for readers interested in gaining further perspective, we have provided several references (see Bailin, 2019; Baron- 
Cohen, 2017, 2019; Bolton, 2018c; Clements, 2019; Elder Robinson, 2017; Salman, 2019;

Zolyomi \& Tennis, 2017). Readers may also contact us for further discussion.

Note that subsets of individuals in all three populations just discussed-the Deaf, blind, and autistic-see their disablement not as a function of their own intrinsic neurological and/or biological state, but as a result of wider society's lack of accommodation for them. This is known as the social model of disability, whereas the medical model provides a deficit-based functional analysis of the body and mind as a machine in need of fixing (e.g., Goodley, 2001).

Becoming familiar with reference language-how disabilities, disorders, and conditions, and how people and groups of people with these, are discussed-is a good first step in vulnerable population cultural immersion, and a prime example of a sociocultural topic with which meteorologists should be familiar when communicating with such individuals. Such awareness makes communication easier while acknowledging and respecting the history, culture, and rights for which inherently vulnerable people have fought. Weather professionals will not successfully communicate with these different cultural groups without meeting them halfway; they cannot be expected to go to meteorologists, rather, meteorologists must take the first steps towards them and then learn how to best meet their needs.

\section{Challenges in Meteorological Communications Involving Color}

Color is a component in nearly all aspects of weather communication and an important and powerful factor in message consistency more generally (see Williams \& Eosco, 2020 for discussion of overall message consistency themes). Ensuring it is used correctly transcends any specific population and is necessary for all individuals to properly receive different kinds of information. Hence, we want to focus, in closing, on those with color vision-processing differences. 
Color comprehension is unique to each individual. One cannot simply rate the ability to perceive shades of green, for example, on a scale from 1 to 10 and then compare this rating with that of another person; we cannot take photos with our eyes and then say "this is what I see! Now show me what you see." What each person sees is simply what that person sees, and it is possible for an individual to not even be aware that this perception of "color" is different relative to others. This is not to say that every person's color vision fluctuates massively; rather, most people generally experience the same shades and ranges of color, with some people's experiences differing more widely in a general manner, such that they have pronounced differences and potential problems with color perception. This subjectivity is a consequence of the way the three types of photoreceptor cone cells work in the human eye to take in light from the short (S), medium (M), and long (L) wavelengths of the electromagnetic spectrum. This light processing system yields the combined shades of red, blue, and green-what we call, and individually experience as, "color" (Purves et al., 2001).

Color is perceived through a complex process in which photoreceptor cells and the brain's visual cortex and associated neural regions process light across different sensitivity levels. When cone cells shift in sensitivity to different bands of the electromagnetic spectrum, a condition known as anomalous trichromacy develops (Machado et al., 2009). Although all three cone cells function in anomalous trichromacy, one does so in a slightly different manner so that there are three possible manifestations of color difference the individual may experience depending on whether the S, M, or L cone cell is affected. This is associated with protanomaly (reduced red lightwave sensitivity), deuteranomaly (reduced green lightwave sensitivity), and tritanomaly (reduced blue lightwave sensitivity). It is important to note that these color 
processing tendencies yield weaknesses in color perception rather than an overarching inability to perceive color.

In contrast, dichromacy is a hereditary, gene-linked condition affecting the $\mathrm{X}$ chromosome, in which one of the photoreceptor cells is missing-the result being that the affected individual loses the ability to accurately perceive an entire spectrum wavelength. This is associated with more severe color vision differences: Protanopia, in which the ability to perceive the red (L) wavelength is lost; deuteranopia, in which the green (M) wavelength is lost; and tritanopia, in which blues (S) are lost. Because of cone overlap on the medium and longwave electromagnetic frequencies, people with red and green deficiencies perceive color similarly and are often collectively referred to as red-green deficient.

It is easy to see, considering this neural complexity, how weather communication challenges associated with color vision do not have a simple, one-size-fits-all solution. Although the human color vision experience is infinitely more subjective than even this listing implies, Table 1 shows the colors with which people who have different processing tendencies tend to have problems. 
Table 1. Different Types of Color Vision-processing Tendency and Their Conflicts.

Processing Tendency Differences and Possible Conflicts

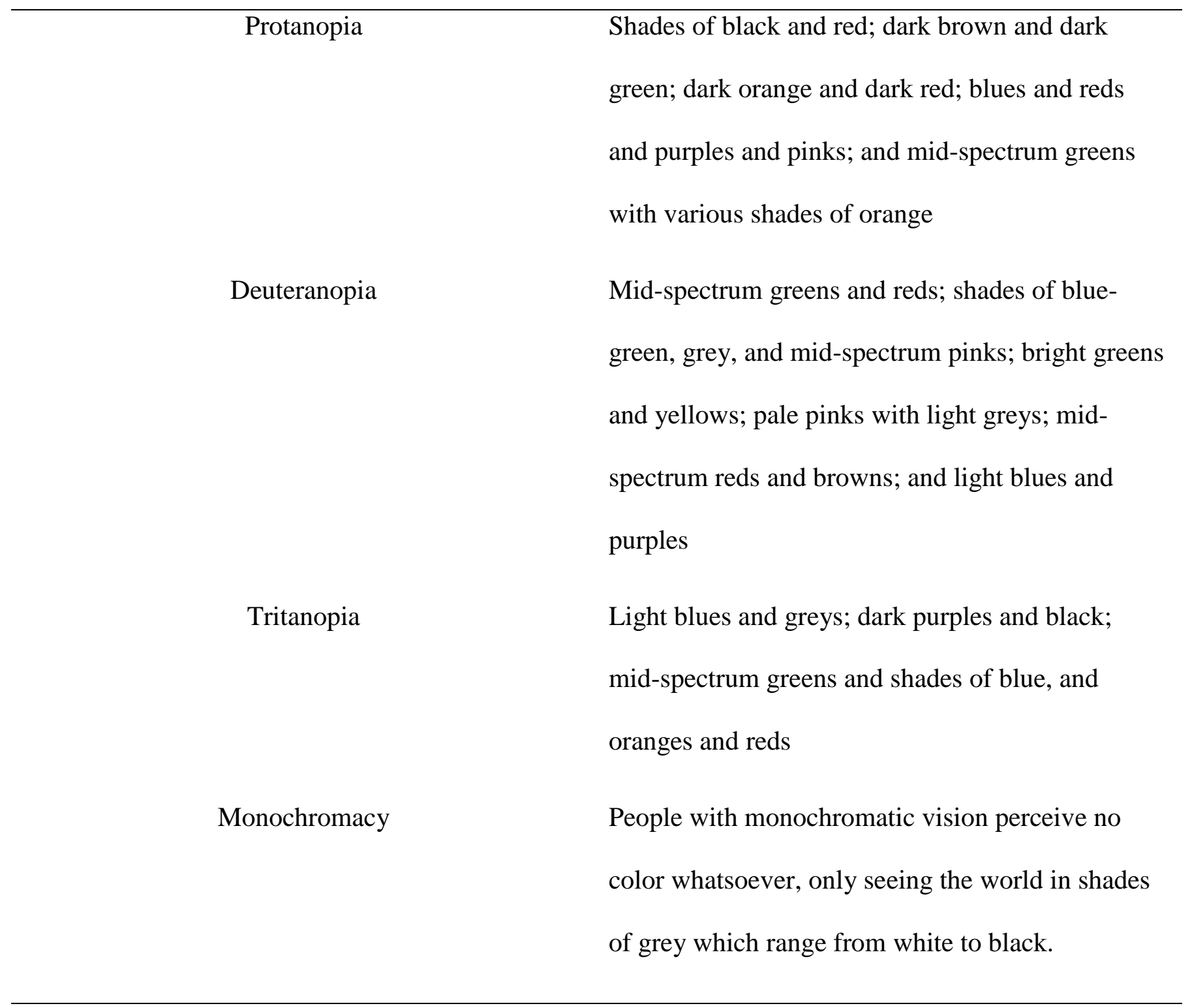

Color vision difference prevalence is not well-established cross-culturally, with researchers estimating its presence is highest in non-Hispanic, White populations and lowest among Black individuals (Xie et al., 2014; although Birch, 2012, suggests rising prevalence rates among men of African ethnicity). It occurs in about $8 \%$ of White men, $0.4 \%$ of White women, and between 
$4 \%$ and $6.5 \%$ of Chinese and Japanese men have a diagnosable color vision-processing difference (Birch, 2012). Similar figures based on gender are found worldwide: Fareed et al. (2015) found color processing differences present for 5.26-11.36\% of men and up to $3.03 \%$ of women in a study of six Indian populations. A study in Ethiopia suggested prevalence rates for men there at $3.6 \%$, and $0.6 \%$ of women (Garedew Woldeamanuel \& Gensa Geta, 2018). It is interesting to note in light of Birch's observation on climbing African prevalence that there is evidence for acquired color vision-processing differences in Africa, linked to linguistic customs that use the same terms for different colors (Rivers, 1901; Davies et al., 1998).

Individual differences in color vision-processing are problematic for meteorologists because they directly impede end-user receipt of critical weather information. Nearly all forms of weather media shared with the public include the use of color to distinguish between pieces of important data, with radar imagery, temperature display maps, and color-coded watch, warning, and advisory (WWA) information the more obvious forms.

Even though there is a practically infinite $\operatorname{array}^{6}$ of individual colors existing across the electromagnetic spectrum, most are simply slight variations of their color neighbors. The human visual system cannot differentiate all of these perceptually, so in practice only a finite number of colors are available and it is easy to create inaccessible color tables. This conundrum is furthered by the human association of color with emotions (e.g., Hanada, 2017; Hemphill, 1996; Mahnke, 1996; Palmer, 2013). Red has been implicated with feelings of excitement and intensity among others, and orange with distress, while purple is seen as dignified, yellow as happy, and blue with

\footnotetext{
${ }^{6}$ In the RGB (red, green, blue) colorspace, colors are described numerically, with each red, green, or blue component in the RGB "triplet" system expressed as an 8-bit integer in decimal (0-255) or hexadecimal (00-FF) form. Multiplying these together $(256 * 256 * 256)$ yields $16,777,215$ individual color combinations; however, these are not all discernable to the human eye.
} 
comfort (e.g., Wexner, 1982). Further, some colors are linked with multiple emotions, and some emotions with multiple colors (Linton, 1999; Saito, 1996). Shades of green have been implicated with feelings of relaxation and refreshment, but also tiredness and guilt. Green has also been shown to evoke thoughts of nature (Davey, 1998; Kaya \& Epps, 2004; Mahnke, 1996; Saito, 1996), hence its use in meteorological displays (Haase et al., 2000).

Meteorological professionals have long capitalized on these linkages. The earliest colorized Doppler radar displays used blues and greens for less intense, and oranges and reds for more intense, reflectivity returns (Gray et al., 1975), and this pattern has since become a radar staple. Similar cool/cool and warm/warm temperature-color associations have been used for decades in forecasting and communicating to weather data consumers. The American Meteorological Society (AMS) once recommended (Doore et al., 1993), based on human factors research (Krebs \& Wolf, 1979; Rice, 1991; Hoffman, 1991; Travis, 1991), that colors selected for meteorological data displays should have familiar relationships with the response the messenger intends to elicit.

Issues associated with basic color compatibility and complementarity, comprising conflicts between textual and other image elements, are, anecdotally, common in weather communication. Other than this type of problem, the biggest barrier to effective and efficient receipt of weather information by those with notable color vision differences is the widely-used rainbow, or "jet," color table (in radar and temperature graphics, for example).

Moreland (2016) discussed the rainbow color table's problems in-depth, noting that it is ordered neither physically nor perceptually. Its lack of physical uniformity translates into a gradient which potentially adds artifacts and obscures meaningful data and that appears to change faster and more sharply in the yellow than green region. Further, although the order of its hues can be learned, there is no natural and intuitive sense of which values are lower or higher in 
a perceptual sense. This creates ambiguity and perceptual overlap for those with color vision differences, making interpretation of gradients and other data details difficult, if not impossible (Moreland, 2016). Figures 1 and 2 simulate both the color spectrum and an example weather map as seen by people with typical color vision and red-green color differences. 


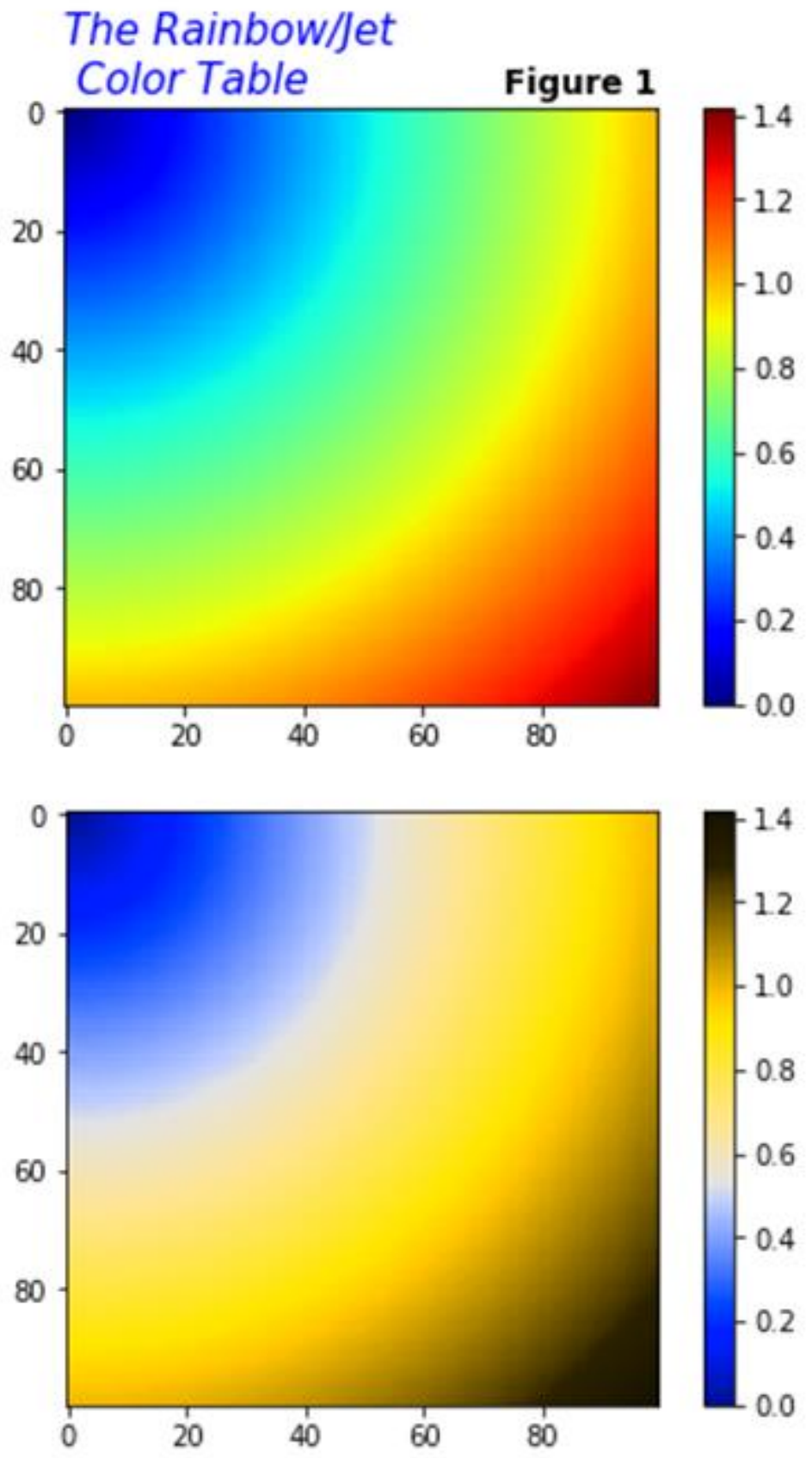



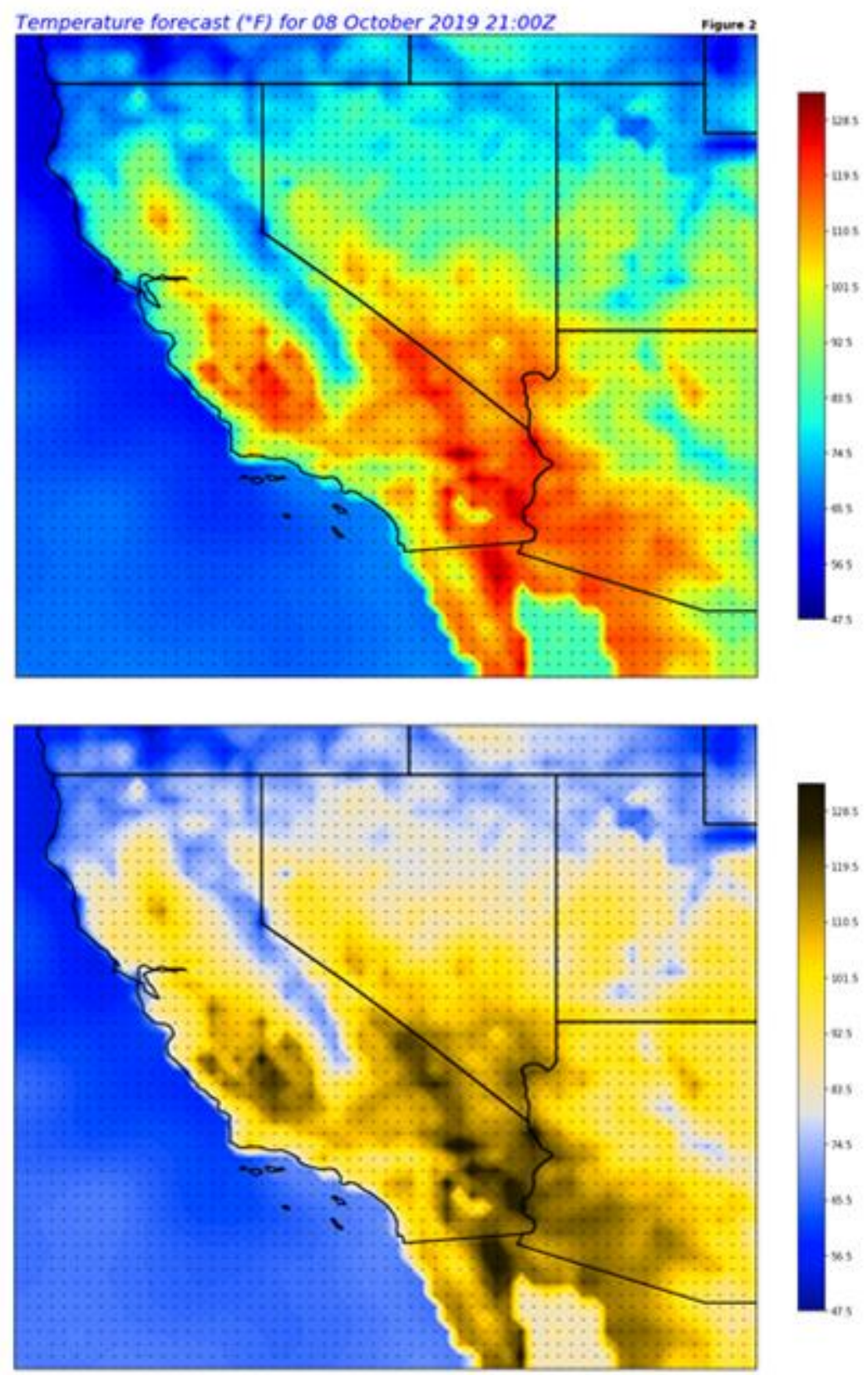
There are a few reliable adjustments meteorologists can make in their universal graphics creation workflows to ensure better accessibility. These are outlined next.

- Contrast and saturation: People who are red-green cone deficient, less sensitive to light at the red end of the electromagnetic spectrum, are often helped by an increase in contrasting luminance. In fact, most individuals with color vision differences do not have trouble distinguishing between color values (luminance), but rather color hues. Therefore, increasing the luminance contrast between two problematic colors is often enough to aid interpretation. With such changes, even those who perceive extreme color differences can distinguish between very light and very dark colors, even if they interpret both to be the same color.

- When text color and background imagery contrast poorly, the text is difficult to read even for those with typical color vision. It is important to consider how text contrasts with background imagery even outside of color, in the context of font style (boldness, italics, weight, etc.). One possible contrast-increasing solution is the reduction of the background image's opacity. Opaque shapes placed behind the text but in front of the image are also effective, as is encapsulating any colored letter with a black border.

- The use of multiple visual cues to aid in detection of the weather threat: Textual captions (e.g., the NWS Storm Prediction Center [SPC] labeling a convective outlook's various threat levels in addition to coloring them, instead of relying on color alone) are of benefit all users. Contour lines are also useful as an aid to discern between data intervals, and when combined with associated text labels, provide greater accessibility to all people. Black contours, even without any color shading, remain true to the data and are immune to issues associated with color interpretation. 


\section{Concluding Thoughts}

Much other work, both behind-the-scenes and more publicly, to address the weather communication needs of several vulnerable populations is ongoing. The American Meteorological Society has a Board on Representation, Accessibility, Inclusion, and Diversity (formerly the Board on Women and Minorities) while the National Weather Association established a Diversity Committee in 2015. Both work to ensure greater inclusion for those with AFNs, within their internal structure as well as the wider weather enterprise. The International Association for Geoscience Diversity (IAGD), meanwhile, is dedicated to increasing the participation of disabled and individually-different people in the broad Earth-related sciences. The IAGD hosts field research programs for college students, provides accessibility resources for geoscientists in need, and works, in general, to advocate for an inclusive environment in the geosciences, regardless of difference.

The NWS has begun to actively address many different challenges. In addition to the efforts we've discussed, homes and communities for the elderly are frequently certified as StormReady ${ }^{\mathrm{TM}}$; NOAA Weather Radio broadcasts are often provided in Spanish; and NWS offices in regions with concentrations of Spanish-speaking individuals issue forecasts in Spanish as well as in English (Trujillo-Falcón et al., 2020). SKYWARN® storm spotter training sessions that include sign language and/or live English captioning for the Deaf and hard-of-hearing are becoming more frequent, and a template is available to produce autism-friendly programs (interested readers can reach out to us for further information). Good progress is being made to support those with AFNs in weather communication. We hope meteorologically-oriented professionals will continue to enhance their understanding of different vulnerabilities and 
actively embrace a framework of intergroup collaboration, in order to better protect life and property.

\section{Acknowledgements}

This paper originated from unused material for a book authored by MJB. MJB was the primary author with support and contributions by HMM and SHH. We are grateful to meteorologist and advocate for the Deaf Trevor Boucher for feedback he provided on an early draft of the material. Note that MJB, who was supported academically during the period of the work by a Graduate Fellowship sponsored by the U.S. National Weather Service and awarded by the American Meteorological Society, brings lived autistic experience to the autism discussion herein. The opinions, conclusions, and recommendations expressed here are those of the authors and do not necessarily reflect the views of the National Weather Service or American Meteorological Society. 


\section{References}

Abramson, D. M, \& Garfield, R. M. (2006). On the edge: Children and families displaced by Hurricane Katrina and Rita face a looming medical and mental health crisis. Columbia University Mailman School of Public Health. https://doi.org/10.7916/D88S4Z4B

American Psychiatric Association. (2013). Autism spectrum disorder. In Diagnostic and statistical manual of mental disorders (5th ed., pp 50-59). American Psychiatric Association.

Bailin, A. (2019, June 6). Clearing up some misconceptions about neurodiversity. Scientific American. https://blogs.scientificamerican.com/observations/clearing-up-somemisconceptions-about-neurodiversity/

Baio, J., Wiggins, L., Christensen, D. L., Maenner, M. J., Daniels, J., Warren, Z., KurziusSpencer, M., Zahorodny, W., Robinson Rosenberg, C., White, T., Durkin, M. S., Imm, P., Nikolaou, L., Yeargin-Allsopp, M., Lee, L.-C., Harrington, R., Lopez, M., Fitzgerald, R. T., Hewitt, A., ... Dowling, N. F. (2018). Prevalence of autism spectrum disorder among children aged 8 years — Autism and Developmental Disabilities Monitoring Network, 11 Sites, United States, 2014. MMWR Surveillance Summaries, 67(6), 1-23. http://doi.org/10.15585/mmwr.ss6706a1

Baron-Cohen, S. (2017). Editorial perspective: Neurodiversity - a revolutionary concept for autism and psychiatry. Journal of Child Psychology and Psychiatry, 58(6), 744-747. https://doi.org/10.1111/jcpp.12703 
Baron-Cohen, S. (2019, April 30). The concept of neurodiversity is dividing the autistic community. Scientific American. https://blogs.scientificamerican.com/observations/theconcept-of-neurodiversity-is-dividing-the-autism-community/

Baxter, A. J., Brugha, T. S., Erskine, H. E., Scheurer, R. W., Vos, T., \& Scott, J. G. (2014). The epidemiology and global burden of autism spectrum disorders. Psychological Medicine, 45(03), 601-613. https://doi.org/10.1017/s003329171400172x

Birch, J. (2012). Worldwide prevalence of red-green color deficiency. Journal of the Optical Society of America A, 29(3), 313-320. https://doi.org/10.1364/JOSAA.29.000313

Blaikie, P., Cannon, T., Davis, I., \& Wisner, B. (2004). At risk: Natural hazards, people's vulnerability and disasters. Routledge.

Bolton, M. J. (2018a). Social attitudes and empathy in the weather enterprise. National Weather Association Monthly Newsletter, 18(7). https://doi.org/10.31234/osf.io/43jbd

Bolton, M. J. (2018b, August). Social biases and the importance of intellectual diversity in the weather enterprise. Talk at the $43^{\text {rd }}$ Annual Meeting of the National Weather Association, St. Louis, MO.

Bolton, M. J. (2018c). With the silence of a thousand cries: Extremes of autistic advocacy. Disability \& Society, 33(6), 980-984. https://doi.org/10.1080/09687599.2018.1454381

Bolton, M. J., \& Ault, L. K. (2018). Diagnosis disclosure increases positivity toward autistic individuals. Psi Chi Journal of Psychological Research: Special Issue on Open Science, 23(3), 110-118. https://doi.org/10.24839/2325-7342.JN23.2.119 
Bolton, M. J, \& Blumberg, W. G. (2015, October). Learning disorders in the meteorological community: Implications for communication and education. Talk at the $40^{\text {th }}$ Annual Meeting of the National Weather Association, Oklahoma City, OK.

Bolton, M. J., Blumberg, W. G., \& Mogil, H. M. (2017). An analysis of the characteristics of autism spectrum conditions for application to weather communication methods in the weather enterprise. OSF Preprints. https://doi.org/10.17605/OSF.IO/TNA3X

Bolton, M. J., Blumberg, W. G., Ault, L. K, Mogil, H. M., \& Hanes, S. H. (2020). Initial evidence for increased weather salience in autism spectrum conditions. Weather, Climate, and Society, 12(2), 293-307. https://doi.org/10.1175/WCAS-D-18-0100.1

Bolton, M. J., \& Hanes, S. H. (2020). Improving prejudicial and stigmatized views towards autistic people in the weather enterprise. NWA Monthly Newsletter, 20(4). https://doi.org/10.31234/osf.io/2gstu

Bolton, M. J., \& Mogil, H. M. (2018a, April). Revisiting the color conundrum: On the use of color in weather displays and implications for hurricane hazard communication. Talk at the $33^{\text {rd }}$ Conference on Hurricanes and Tropical Meteorology, hosted by the American Meteorological Society, Ponte Vedra, FL.

Bolton, M. J., \& Mogil, H. M. (2018b, January). Revisiting the color conundrum: On the use of color in weather displays. Talk at the $98^{\text {th }}$ Annual Meeting of the American Meteorological Society, Austin, TX.

Bolton, M. J., Mogil, H. M., Aizenman, H., Ault, L. K., \& Blumberg, W. G. (2019, January). Color vision deficiencies and weather communication: A universally-accessible, proofof-concept color table for use in weather data displays. Poster at the $18^{\text {th }}$ Annual Student 
Conference of the $99^{\text {th }}$ Annual Meeting of the American Meteorological Society, Phoenix, AZ.

Bolton, M. J., Wise, G., \& Blumberg, W. G. (2016, October). Color blindness in the weather enterprise: Discussion and a look at solutions. Poster at the $41^{\text {st }}$ Annual Meeting of the National Weather Association, Norfolk, VA.

Borland, D., \& Taylor, R. M. II. (2007). Rainbow color map still considered harmful.

Visualization Viewpoints, March/April, 14-17.

\section{http://people.cs.vt.edu/ npolys/IT/FDI/spring2011/color_07.pdf}

Brosnan, M., \& Mills, E. (2016). The effect of diagnostic labels on the affective responses of college students towards peers with “Asperger”s Syndrome’ and “Autism Spectrum Disorder." Autism, 20(4), 388-394. https://doi.org/10.1177/1362361315586721

Casserly, M. (2006). Double jeopardy: Public education in New Orleans before and after the storm. In C. Hartman \& G. D. Squires (Eds.), There is no such thing as a natural disaster: Race, class, and Hurricane Katrina (pp. 197-214). Routledge.

Chung, D. H. S., D. Archambault, R. Borgo, D. J. Edwards, R. S. Laramee, and M. Chen, 2016: How ordered is it? On the perceptual orderability of visual channels. Proceedings of the Eurographics Conference on Visualization, 35.

Clements, T. (2019, August 26). What is autism? How the term became too broad to have meaning any more. The Guardian. https://www.theguardian.com/commentisfree/2019/aug/26/autism-neurodiversity-severe

Davey, P. (1998) True colors: The glorious polychromy of the past suggests a strong historical need for color, despite current reductive fashions. Architectural Review, 204, 34-36. 
Davies, I. R. L., Laws, G., Corbett, G. G., \& Jerrett, D. J. (1998). Cross-cultural differences in colour vision: Acquired 'colour-blindness' in Africa. Personality and Individual Differences, 25(6), 1153-1162. https://doi.org/10.1016/S0191-8869(98)00150-0

Doore, G. S., Eustis, A. C., Jones, D., Leep, R., Lincoln, J., MacDonald, A. E., Mandics, P. A., Ryan, R. T., Schiavone, J. A., \& Schiessl, D. (1993). Guidelines for using color to depict meteorological information: MPS subcommittee for color guidelines. Bulletin of the American Meteorological Society, 74, 1709-1713.

Elder Robinson, J. (2017, April 5). The controversy around autism and neurodiversity.

Psychology Today. https://www.psychologytoday.com/us/blog/my-lifeaspergers/201704/the-controversy-around-autism-and-neurodiversity

Fareed, M., Azeem Anwar, M., \& Afzal, M. (2015). Prevalence and gene frequency of color vision impairments among children of six populations from North Indian region. Gene \& Diseases, 2(2), 211-218. https://doi.org/10.1016/j.gendis.2015.02.006

Fothergill, A., \& Peek, L. (2004). Poverty and disasters in the United States: A review of the sociological literature. Natural Hazards, 32, 89-110.

Fox, M. H., White, G. W., Rooney, C., \& Rowland, J. L. (2007). Disaster preparedness and response for persons with mobility impairments. Journal of Disability Policy Studies, 17(4), 196-205.

Garedew Woldeamanuel, G., \& Gensa Geta, T. (2018). Prevalence of color vision deficiency among school children in Wolkite, Southern Ethiopa. BMC Research Notes, 11, 838. https://doi.org/10.1186/s13104-018-3943-Z 
Goodley, D. (2001). 'Learning difficulties', the Social Model of Disability and impairment: Challenging epistemologies. Disability \& Society, 16(2), 207-231.

Gray, G. R., Serafin, R. J., Atlas, D., Rinehart, R. E., \& Boyajian, J. J. (1975). Real-time color Doppler radar display. Bulletin of the American Meteorological Society, 56, 580-588.

Haase, H., Bock, M., Hergenröther, E., Knöpfle, C., Koppert, H.-J., Schröder, F., Trembilski, A., \& Weidenhausen, J. (2000). Computers \& Graphics, 24(3), 391-397. https://doi.org/10.1016/S0097-8493(00)00035-2

Hanada, M. (2017). Correspondence analysis of color-emotion associations. Color Research \& Application, 43(2), 224-237. https://doi.org/10.1002/col.22171

Hanes, S. H., \& Bolton, M. J. (2020). Some notes on the development of an autism-accessible SKYWARN® storm spotter program. NWA Monthly Newsletter, 20(1). https://doi.org/10.31234/osf.io/sbthx

Hemingway, L., \& Priestly, M. (2006). Natural hazards, human vulnerability, and disabling societies: A disaster for disabled people? The Review of Disability Studies, 2(3), 57-67.

Hemphill, M. (1996). A note on adults' color-emotion associations. The Journal of Genetic Psychology, 157(3), 275-281.

Hobson, J., \& Cote, J. (2019). 'Could you draw a dot within 50 miles of your house?': Why the U.S. may have a geography literacy problem. WBUR. https://www.wbur.org/hereandnow/2019/04/19/map-skills-severe-weather

Hoffman, R. R. (1991). Human factors psychology in the support of forecasting: The design of advanced meteorological workstations. Weather \& Forecasting, 6, 98-110. https://doi.org/10.1175/1520-0434(1991)006\%3C0098:HFPITS\%3E2.0.CO;2 
Hopfe, A. (1999, July). The culture of blindness. http://www.blindcanadians.ca/publications/cbm/14/culture-blindness

Hufschmidt, G. (2011). A comparative analysis of several vulnerability concepts. Natural Hazards, 58, 621-643. https://doi.org/10.1007/s11069-011-9823-7

Hull, L., Petrides, K. V., Allison, C., Smith, P., Baron-Cohen, S., Lai, M.-C., \& Mandy, W. (2017). "Putting on my best normal": Social camouflaging in adults with autism spectrum conditions. Journal of Autism and Developmental Disorders, 47(8), 2519-2534. https://doi.org/10.1007/s10803-017-3166-5

Kapp, S. K., Gillespie-Lynch, K., Sherman, L. E., \& Hutman, T. (2013). Deficit, difference, or both? Autism and neurodiversity. Developmental Psychology, 49(1), 5971. https://doi.org/10.1037/a0028353

Kaya, N., \& Epps, H. H. (2004). Relationship between color and emotion: A study of college students. College Student Journal, 38, 396-405.

Kenny, L., Hattersley, C., Molins, B., Buckley, C., Povey, C., \& Pellicano, E. (2016). Which terms should be used to describe autism? Perspectives from the UK autism community. Autism, 20, 442-462. https://doi.org/10.1177/1362361315588200

Krebs, M. J., \& Wolf, J. D. (1979). Design principles for the use of color in displays. Proceedings of the Society for Information Display, 20(1), 10-15.

Lai, M.-C., Lombardo, M. V., Ruigrok, A. N., Chakrabarti, B., Auyeung, B., Szatmari, P., Happé, F., Baron-Cohen, S., \& MRC AIMS Consortium. (2017). Quantifying and exploring camouflaging in men and women with autism. Autism, 21(6), 690-702. https://doi.org/10.1177/1362361316671012 
Linton, H., 1999: Color in architecture: Design methods for buildings, interiors and urban spaces. McGraw Hill.

Liss, M., Mailloux, \& Erchull, M. J. (2008). The relationships between sensory processing sensitivity, alexithymia, autism, depression, and anxiety. Personality and Individual Differences, 45(3), 255-259. https://doi.org/10.1016/j.paid.2008.04.009

Machado, G. M., Oliveira, M. M., \& Fernandes, L. A. F. (2009). A physiologically-based model for simulation of color vision deficiency. IEEE Transactions on Visualization and Computer Graphics, 15(6), 1291-1298.

Mahnke F. (1996). Color, environment, human response. Van Nostrand Reinhold.

Mitchell, T., Haynes, K., Hall, N., Choong, W., \& Oven, K. (2008). The role of children and youth in communicating disaster risk. Children, Youth and Environments, 18(1), 254279.

Moreland, K. (2016). Why we use bad color maps and what you can do about it. Proceedings of Human Vision and Electronic Imaging (HVEI). https://doi.org/10.2352/ISSN.24701173.2016.16.HVEI-133

Morrison, K. E., DeBrabander, K. M., Faso, D. J., \& Sasson, N. J. (2019). Variability in first impressions of autistic adults made by neurotypical raters is driven more by characteristics of the rater than by characteristics of autistic adults. Autism, 23(7), 18171829. https://doi.org/10.1177/1362361318824104

Neil, L., Olsson, N. C., \& Pellicano, E. (2016). The relationship between intolerance of uncertainty, sensory sensitivities, and anxiety in autistic and typically developed children. 
Journal of Autism and Developmental Disorders, 46, 1962-1973. https://doi.org/10.1007/s10803-016-2721-9

Oliva, A., Mack, M. L., Shrestha, M., \& Peeper, A. (2004). Identifying the perceptual dimensions of visual complexity of scenes. Proceedings of the Annual Meeting of the Cognitive Science Society, 26. https://escholarship.org/uc/item/17s4h6w8

Osofsky, J. D., Osofsky, H. J., \& Harris, W. W. (2007). Katrina’s children: Social policy considerations for children in disasters. Social Policy Report, 21(1), 3-18.

Padden, C., \& Humphries, T. (1990). Deaf in America: Voices from a culture. Harvard University Press.

Padden, C., \& Humphries, T. (2005, February 2). An exploration of Deaf culture in America. National Public Radio. https://www.npr.org/templates/story/story.php?storyId=4474055

Palmer, S. E. Schloss, K. B., Xu, Z., \& Prado-León, L. R. (2013). Music-color associations are mediated by emotion. Proceedings of the National Academies of Science, 110(22), 88368841. https://doi.org/10.1073/pnas.1212562110

Patterson, O., Weil, F., \& Patel, K. (2010). The role of community in disaster response: Conceptual models. Population Research and Policy Review, 29, 127-141. https://doi.org/10.1007/s11113-009-9133-x

Peek, L., \& Stough, L. M. (2010). Children with disabilities in the context of disaster: A social vulnerability perspective. Child Development, 81(4), 1260-1270.

Phillips, B. D., \& Morrow, B. H. (2007). Social science research needs: Focus on vulnerable populations, forecasting, and warnings. Natural Hazards Review, 8(3), 61-68. https://doi.org/10.1061/(asce)1527-6988(2007)8:3(61) 
Pierce, B. (2008, November). No such thing as blind culture. Braile Monitor. https://nfb.org/images/nfb/publications/bm/bm08/bm0810/bm081007.htm

Purves, D., G. J. Augustine, D. Fitzpatrick, L. C. Katz, A.-S. LaMantia, J. O. McNamara, \& Williams, S. M. (Eds.). (2001). Cones and color vision (chapter 11 section). In Purves et al. Neuroscience, $2^{\text {nd }}$ edition. Sinauer Associates.

Rice, J. F. (1991). Ten rules for color coding. Information Display, 7, 12-14.

Redlener, I. E., Abramson, D. M., Stehling-Ariza, T., \& Fuller, E. J. (2007). The legacy of Katrina's children: Estimating the numbers of at-risk children in the Gulf Coast states of Louisiana and Mississippi. Columbia University Mailman School of Public Health. https://doi.org/10.7916/D8891FMF

Rivers, W. H. R. (1901). Introduction. In A. C. Haddon (Ed.), Reports on the Cambridge Anthropological Expedition to the Torres Straits. Cambridge University Press.

Rooney, C., \& White, G. W. (2007). Narrative analysis of a disaster preparedness and emergency response survey from persons with mobility impairments. Journal of Disability Policy Studies, 17(4), 206-215.

Rowland, J. L., White, G. W., Fox, M. H., \& Rooney, C. (2007). Emergency response training practices for people with disabilities. Journal of Disability Policy Studies, 17(4), 216222.

Saito, M. (1996). Comparative studies on color preference in Japan and other Asian regions, with special emphasis on the preference for white. Color Research \& Applications., 21(1), 3549. 
Salman, S. (2019, October 2). Simon Baron-Cohen: 'Neurodiversity is the next frontier. But we're failing autistic people.' The Guardian. https://www.theguardian.com/society/2019/oct/02/simon-baron-cohen-autismneurodiversity-brains-money

Sasson, N. J. \& Morrison, K. E. (2019). First impressions of adults with autism improve with diagnostic disclosure and increased autism knowledge of peers. Autism: The International Journal of Research and Practice, 23, 50-59.

Sasson, N. J., Faso, D. J., Nugent, J., Lovell, S., Kennedy, D. P., \& Grossman, R. B. (2017). Neurotypical peers are less willing to interact with those with autism based on thin slice judgments. Scientific Reports, 7, 40700. https://doi.org/10.1038/srep40700

Sherman-Morris, K., Pechacek, T., Griffin, D. J., \& Senkbeil, J. (2020). Tornado warning awareness, information needs and the barriers to protective action of individuals who are blind. International Journal of Disaster Risk Reduction, 50, 101709. https://doi.org/10.1016/j.ijdrr.2020.101709

South, M., \& Rodgers, J. (2017). Sensory, emotional and cognitive contributions to anxiety in autism spectrum disorders. Frontiers in Human Neuroscience, 11. https://doi.org/10.3389/fnhum.2017.00020

Spence, P. R., Lachlan, K., Burke, J. M., \& Seeger, M. W. (2007). Media use and information needs of the disabled during a natural disaster. Journal of Health Care for the Poor and Underserved, 18, 394-404.

Travis, D. (1991). Effective color displays: Theory and practice. Academic Press. 
Trujillo-Falcón, J. E., Bermúdez, O., Negrón-Hernández, K., Lipski, J., Leitman, E., \& Berry, K. (2020). Hazardous weather communication en Español: Challenges, current resources, and future practices. Bulletin of the American Meteorological Society. Early online release. https://doi.org/10.1175/bams-d-20-0249.1

U.S. Centers for Disease Control. (2020). Prevalence of autism spectrum disorder among children aged 8 years - Autism and Developmental Disabilities Monitoring Network, 11 sites, United States, 2016. https://www.cdc.gov/mmwr/volumes/69/ss/ss6904a1.htm?s_cid=ss6904a1_w

U.S. Department of Health and Human Services. (2019, March 28) At-risk individuals. Retrieved January 4, 2021 from https://www.phe.gov/Preparedness/planning/abc/Pages/atrisk.aspx

van Willigen, M., Edwards, T., Edwards, B., \& Hessee, S. (2002). Riding out the storm: Experiences of the physically disabled during Hurricanes Bonnie, Dennis, and Floyd. Natural Hazards Review, 3(3), 98-106.

Wexner, L. B. (1982). The degree to which colors are associated with mood-tones. Journal of Applied Psychology, 6, 432-435.

White, B. (2006). Disaster relief for deaf persons: Lessons from Hurricanes Katrina and Rita. The Review of Disability Studies, 2(3), 49-56. https://scholarspace.manoa.hawaii.edu/bitstream/10125/58269/1/1034.pdf

Williams, C. A., \& Eosco, G. (2020). Is a consistent message achievable? Defining 'message consistency' for weather enterprise researchers and practitioners. Bulletin of the American Meteorological Society. Early online release. https://doi.org/10.1175/BAMSD-18-0250.1 
Wisner, B. (2016). Vulnerability as concept, model, metric, and tool. Oxford Research Encyclopedia of Natural Hazards. Oxford University Press. https://doi.org/10.1093/acrefore/9780199389407.013.25

Xie, J. Z., Tarczy-Hornoch, K., Lin, J., Cotter, S. A., Torres, M., Varma, R., \& Multi-Ethnic Pediatric Eye Disease Study Group. (2014). Color vision deficiency in preschool children: The Mult-Ethnic Pediatric Eye Disease Study. Ophthalmology, 121(7), 14691474. https://doi.org/10.1016/j.ophtha.2014.01.018

Zolyomi, A., \& Tennis, J. T. (2017). Autism prism: A domain analysis paper examining neurodiversity. NASKO, 6, 139-172. 